\title{
PRODUÇÃO DE BIOGÁS ATRAVÉS DO APROVEITAMENTO DE DEJETOS
}

\section{PRODUCTION OF BIOGAS THROUGH USE OF WASTE}

\author{
Creusa Carvalho da Costa ${ }^{1}$ \\ Ana Cristina Alves Rodrigues ${ }^{2}$ \\ Ivanilza Moreira de Andrade ${ }^{3}$ \\ José Machado Moita Neto ${ }^{4}$
}

Submetido: 30/03/2021 / Aprovado: 28/10/2021 / Publicado: 10/12/2021.

\begin{abstract}
Resumo
Objetivamos contemplar os aspectos econômico, ambiental e tecnológico da produção de biogás proveniente de dejetos em ambientes rurais e urbanos. Para o desenvolvimento desta pesquisa realizou-se a análise de artigos científicos indexados nas bases de dados: Scielo, Web of Science, Science direct, Google scholar referentes à temática produção de biogás através de dejetos produzidos durante os anos de 2011 a 2021. Os trabalhos eleitos foram os que tratavam de questões socioambientais, usos de energia, produção de biogás, valoração de produção de biogás consecutivo de dejetos vegetais e animais, limites da produção de biogás, fatores que influenciam na economia da produção de biogás, critérios estes estabelecidos pelos pesquisadores, com intuito de investigar a produção de biogás através de dejetos. A pesquisa referente à abordagem da produção de biogás decorrente de dejetos facilitou a busca e o refinamento de conceitos e discussões contextualizadas no âmbito nacional e internacional a cerca da temática discutida no desenvolvimento da produção desta pesquisa.
\end{abstract}

Palavras-chave: Energia. Sustentabilidade. Gás.

\begin{abstract}
We aim to contemplate the economic, environmental and technological aspects of biogas production from waste in rural and urban environments. For the development of this research, the analysis of scientific articles indexed in the following databases was carried out: Scielo, Web of Science, Science direct, Google scholar referring to the theme of biogas production through waste produced during the years 2011 to 2021 . The selected works were those dealing with socioenvironmental issues, energy use, biogas production, valuation of consecutive biogas production from plant and animal waste, limits of biogas production, criteria established by the researchers, with the aim of investigating the production of biogas through waste. The research referring to the approach to the production of biogas from waste facilitated the search and refinement of concepts and contextualized discussions in the national and international scope about the theme discussed in the development of the production of this research.
\end{abstract}

Keywords: Energy, Sustainability, Gas.

\footnotetext{
${ }^{1}$ Mestranda em Desenvolvimento e Meio Ambiente. Universidade Federal do Piauí. E-mail: creusa-ufpi@outlook.com

${ }^{2}$ Mestranda em Desenvolvimento e Meio Ambiente. Universidade Federal do Piauí. E-mail: cristinaalvesrodrigues440@gmail.com

${ }^{3}$ Doutora em Botânica. Professora na Universidade Federal do Piauí. E-mail: ivanilzaandrade@hotmail.com

${ }^{4}$ Doutor em Química. Professor na Universidade Federal do Piauí. E-mail: jose.machado.moita.neto@gmail.com DOI: http://dx.doi.org/10.24021/raac.v19i1.6228

Vol. 19, N. 1 (2022) 


\section{INTRODUÇÃo}

A utilização e produção de biogás é de suma relevância para abordagem econômica nos âmbitos rurais e urbanos. Nesse viés para se transformar o biogás em energia elétrica é necessário à utilização de motores de combustão a gás e posteriormente um gerador de energia elétrica (TIETZ et al., 2013).

A falta de energia elétrica limita o desenvolvimento de atividades que promovem emprego e renda, acarretando a exclusão social pela ausência de recursos necessários para crescimento local (VELÁZQUEZ et al., 2014).

O biogás pode ser utilizado tanto para produção de eletricidade quanto para geração de calor, através da transformação de dejetos em fontes de energia com múltiplas funções, seja gerando crédito de carbono, para autonomia energética das propriedades e geração de energia para residências e indústrias, trazendo benefícios econômicos e ambientais principalmente para os produtores rurais (SUNADA et al., 2012; STRASSBURG et al., 2016).

Portanto a produção de biogás tem sido uma alternativa para os produtores rurais, pois esta possibilita redução da contaminação do solo e água. Entretanto a produção do biogás apresenta alguns fatores negativos, acarretados pela geração de dióxido de carbono e metano.

A pesquisa objetivou contemplar os aspectos econômico, ambiental e tecnológico da produção de biogás proveniente de dejetos de animais em ambientes rurais e urbanos.

\section{REFERENCIAL TEÓRICO}

\subsection{Produção de biogás}

Diferentes tipos de resíduos têm potencial de produção de biogás: dejetos de bovinos, suínos, lodo de esgoto, resíduos de frutas e vegetais (QUIAO et al., 2011).

Existem diversos métodos para a realização de tratamento residuais de dejetos, tais como decantação, tratamento de esterqueira e biodigestão anaeróbica, esta última se traduz em uma tecnologia eficiente, onde a obtenção de biogás é permitida, pois além de amortizar o custo de instalação da tecnologia, soluciona o problema de saneamento da disposição destes resíduos, consequentemente apresentando vantagens dessa reutilização dos dejetos (DHANALAKSHMI; RAMANUJAN, 2012; FILHO et al., 2018).

O biogás produzido através de digestão anaeróbia é composto de metano $(\mathrm{CH} 4)$, dióxido de carbono (CO2) e sulfeto de hidrogênio (H2S), este gás contém aproximadamente 36 a $50 \%$ de metano (CH4) e de 15 a $60 \%$ (CO2) de dióxido de carbono (RYCHEBOSH et al., 2011).

Um fator importante dessas fontes de energia é que muitas delas podem ser usadas no mesmo local onde foram geradas, descentralizando a produção de energia, minimizando a logística e criando possibilidades de autossuficiência energética para diversos produtores (OLIVEIRA et al., 2016).

\subsection{Alternativas de produção por resíduos vegetais}

O biogás é uma das alternativas de reaproveitamento da biomassa, bem como dos resíduos vegetais agrícolas gerados (SITORUS; PANJAITAN, 2013). Portanto, o reaproveitamento da biomassa remanescentes da agricultura para a produção de biogás, além de evitar a acumulação de resíduos, fundamental para reduzir a dependência de fertilizantes químicos importados, visto que a 
tecnologia do biogás pode ter como coproduto de fertilizantes organominerais (KOMINKO et al., 2017).

A obtenção do biogás, os materiais orgânicos submetidos ao processo de digestão anaeróbia por meio de biodigestor produzem um adubo orgânico, o biofertilizante, que pode ser utilizado na agricultura como fonte de nutrientes para as culturas (BOCOLI et al., 2016).

O emprego de fertilizantes orgânicos tem papel fundamental no aumento de produção, em virtude que, podem melhorar as características físicas, químicas e biológicas do solo, além de promover um desenvolvimento vegetativo adequado à obtenção de produtividade economicamente viável a produtores rurais (SILVA et al., 2012).

\subsection{Produção do biogás consecutivo da suinocultura}

O biogás é uma das alternativas de reaproveitamento da biomassa. A produção de energias renováveis através do reaproveitamento de dejetos contribui para o aumento da matriz energética, além de possuir características sustentáveis, na busca de reduzir o lançamento inadequado de dejetos no meio ambiente (SITORUS; PANJAITAN, 2013; SONIA et al., 2016).

Os dejetos da suinocultura apresentam uma vantagem para produzir biogás, tendo capacidade para produção de até $560 \mathrm{~m}^{3}$ de biogás por toneladas, dependendo da composição e tratamento (DOS SANTOS; NARDI JUNIOR, 2013).

O Brasil é um grande gerador de resíduos orgânicos, baseado na sua população, larga produção de alimentos, combustíveis, criação de animais e diversos processos produtivos que eliminam subprodutos passíveis de aproveitamentos na produção de energia renovável (OLIVEIRA; FERREIRA, 2016).

Os resíduos animais são o melhor alimento para os biodigestores, pelo fato de já saírem dos seus intestinos carregados de bactérias anaeróbicas (BONTURI; VAN DIJK, 2012).

Dessa forma, estudar os indicadores físico-químicos e microbiológicos e como eles interagem entre si é uma importante ferramenta, uma vez que estes podem aumentar o desempenho dos processos biodegradativos, elevar as concentrações de biogás e também reduzir a emissão de gases de efeito estufa liberados ao ambiente (FERREIRA et al., 2017).

Em longo prazo há uma tendência de esgotamento das fontes tradicionais de energia, como o carvão e o petróleo, sendo emergente o surgimento de novas fontes, especialmente as renováveis. Nesse viés as Bactérias mediando tais reações exaurem o oxigênio residual no digestor, proporcionando condições adequadas para o processo final (metanogênese), no qual bactérias anaeróbicas controlam a produção de metano dos produtos da acidogênese (BOND; TEMPLETON, 2011; MILANEZ et al., 2018).

\subsection{Desenvolvimento sustentável e produção de biogás}

O desenvolvimento sustentável visa à manutenção das bases vitais da produção e da reprodução do homem, bem como de suas atividades, garantindo uma relação satisfatória do homem com o meio ambiente, para que futuras gerações também possam desfrutar dos recursos naturais (BORTOLON; MENDES, 2014).

Dessa forma é de suma importância abordar as três dimensões do desenvolvimento sustentável na produção de biogás. A primeira dimensão aborda questões ambientais no que diz respeito à análise de um modelo de produção e consumo que seja compatível com a capacidade de resiliência dos ecossistemas; a segunda dimensão refere-se à econômica, à matriz energética, tratando a relevância da tecnologia e utilização de fontes energéticas alternativas. E a terceira 
corresponde ao social, que permite uma análise sobre a necessidade da melhoria da qualidade de vida (NASCIMENTO, 2012).

Com a utilização dos resíduos, os autores (GOLDEMBERG; PALETTA et al., 2012) consideram como benefícios a preservação do solo, mananciais e águas subterrâneas (dimensão ambiental), a biodigestão evita o contato humano aos resíduos reduzindo a proliferação de pragas e outras doenças correlacionadas à falta de saneamento básico (BARBOSA; LANGER, 2011).

\section{Metodologia}

A pesquisa fundamenta-se na abordagem qualitativa correspondendo a um processo descritivo e analítico (OLIVEIRA, 2014). Consistiu na análise de artigos científicos indexados nas bases de dados: Scielo, Web of Science, Science direct, Google scholar referentes à temática produção de biogás através de dejetos. Utilizaram-se as palavras-chave: biogás, biogás and energy, production of biogás bywaste como ferramentas de busca.

Selecionaram-se trabalhos que apresentavam os descritores de busca no título, resumo e palavras-chave do artigo, com ênfase nos anos de 2011 a 2021. Posteriormente realizou-se a verificação aprofundada dos mesmos.

Os trabalhos eleitos foram os que tratavam de questões socioambientais, usos de energia, produção de biogás, valoração de produção de biogás consecutivo de dejetos animais, limites da produção de biogás, fatores que influenciam na economia da produção de biogás, critérios estes estabelecidos pelos pesquisadores, com intuito de investigar a produção de biogás através de dejetos.

Os dados foram descritos baseando-se nos aspectos econômico, social, ambiental e tecnológico da produção de biogás oriundos de dejetos.

\section{RESUltados E DisCUSSÃo}

O gerenciamento ambiental é uma necessidade que se apresenta incontestável e requer não apenas a organização e a sistematização das fontes geradoras, mas fundamentalmente o despertar de uma consciência coletiva quanto às responsabilidades individuais no trato com esta questão (MULLER et al., 2013).

Constatou-se que os trabalhos selecionados para a realização da discussão abordavam questões econômicas e ambientais frente à dialética de produção de energia através do biogás, no entanto, percebeu-se que mesmo apresentando potencial para produção, as condições econômicas para implantação e desenvolvimento de instalações são precárias principalmente quando se trata dos pequenos produtores rurais.

As limitações e potencialidades da produção de biogás incluem propostas para busca do uso de reformas tecnológicas e ambientais. Dessa forma as ações educacionais contribuem com a abordagem sobre o uso de energia gerado de dejetos de modo sustentável, garantindo a utilização tanto em meios rurais, quanto urbano. Com isso a literatura cientifica destaca que as informações presentes nos contextos sociais, ambientais e educacionais promovem construção da visão crítica e sistêmica em relação aos meios de produção de energia.

Dados mostram que as pesquisas realizadas entre os anos de 2014 a 2021 apresentam referencial e discussão com maiores abrangências no que se refere às tecnologias utilizadas para o desenvolvimento do aproveitamento de dejetos para produção de biogás.

Ao avaliarem a degradação e o potencial de produção de biogás através do biopolímero de amido de batata por digestão anaeróbia em fase mesofílica com os reatores em operação batelada, 
(Heydt et al., 2020) relataram que a adição de apenas $7 \%$ de biopolímero de amido de batata, apresentou melhores resultados referentes à composição do biogás.

Diante da necessidade de obtenção e aperfeiçoamento de tecnologias econômicas e ambientalmente sustentáveis para a geração de energia, a utilização de biodigestores para a produção de biogás como combustível representa um potencial expressivo, devido principalmente ao elevado poder calorífico do gás produzido. O processo anaeróbio de produção do biogás com utilização de matéria orgânica como matéria-prima requer condições específicas por se tratar de um sistema microbiológico, contudo, mantidas as condições operacionais otimizadas, este constitui um processo eficiente, conforme se verifica nos estudos já realizados (ARAÚJO, 2017).

Nesse contexto verificou-se que o consumo é uma temática atual que busca alternativas econômicas em proveito para a sustentabilidade, apesar disso, há uma escassez de pesquisas que aprofundem o conhecimento sobre esse tipo de consumo como modelo de negócios, seus impactos sobre a sustentabilidade e como alinhar interesses com os seus principais interessados para garantir a longevidade de suas operações (COHEN; KIETZMANN, 2014).

Dessa forma com crescimento de consumo é de suma importância a elaboração de projetos e tecnologias para produção de biogás proveniente de dejetos vegetais e animais na busca de alcançar a sustentabilidade e fazer com que toda a população tenha acesso ao nexo energia.

O reaproveitamento industrial dos alimentos desperdiçados é considerado atrativo para a produção de biogás como aproveitamento energético (FERREIRA, 2015). Experiências realizadas nesse sentido demostram que ametanização dos resíduos alimentares é uma alternativa viável para o tratamento e a valoração desse resíduo (LI et al., 2011; BROWNE et al., 2013). Todos esses fatores tem sido alvo de estudos e inúmeros trabalhos acerca dos mesmos já foram publicados, o que ressalta mais ainda sua importância quanto a sua viabilidade econômica e ambiental (RODRIGUES; AQUINO; ESTEVAM, 2011).

Segundo Rodnei (2013) mesmo que a criação de usinas de incineração de resíduos encontre incentivos em algumas diretrizes governamentais de saneamento básico, as quais indicam a busca de alternativas ao aterramento do lixo, a solução não é unânime, sobretudo pelas preocupações quanto ao monitoramento dos gases produzidos na queima.

Já no que se refere aos resíduos decorrentes da produção animal, provocam alterações negativas na qualidade de vida da população, visto que o descarte de dejetos em locais inapropriados geram doenças, desconforto quanto ao odor ocasionado pelo chorume, bem como eutrofização e lixiviação (SILVA; AMARAL, 2013).

Com forte aplicação no setor agroindustrial, o uso do biogás como matéria prima para a geração de energia elétrica está diretamente ligado à sustentabilidade e tem se mostrado muito interessante, tanto para geração de energia elétrica como alternativa para a disposição de resíduos sólidos e efluentes orgânicos (LORA; VENTURINI et al., 2012; ABREU et al., 2014).

É notório que por meio da mudança nos valores e práticas, os servidores se transformarão em novos atores e contribuirão para a construção de uma nova cultura organizacional, proporcionando um meio ambiente equilibrado, com a inserção de critérios sociais e ambientais na rotina administrativa, acarretando em um diferencial estratégico (SOUSA; CARVALHO, 2015).

Conforme Lora e Venturini et al. (2012) salientam, que a utilização do biogás não deve ser tida como a solução para os problemas energéticos do país, mas como uma complementação para a matriz atual, que deve ser composta por várias fontes alternativas. Outra forma de estimular o mercado renovável é estabelecer o direito ao recebimento de indenização com base no valor de mercado da energia despejada na rede (ÉL PAÍS, 2018).

Produzir energias renováveis reaproveitando dejetos gerados no agronegócio contribui para o aumento da matriz energética nacional, além de possuir um viés sustentável, reduzindo o 
lançamento inadequado de dejetos no meio ambiente, e proporcionando o surgimento de novos negócios, geração de renda e maior desenvolvimento econômico e social (SONIA et al., 2016).

Baseando-se nas premissas anteriormente citadas, a produção de biogás está sendo de suma relevância no processo de investimentos econômicos, tecnológico e ambiental fundamentada na investigação científica.

De acordo com o levantamento de dados pesquisados e estudados foi possível compreender os limites e potencialidades para obtenção de dados referentes à produção de biogás através de dejetos no qual são essenciais para interligar os eixos econômico, social, tecnológico e ambiental.

\section{CONSIDERAÇÕES FINAIS}

A pesquisa referente à abordagem da produção de biogás decorrente de dejetos facilitou a busca e o refinamento de conceitos e discussões contextualizadas no âmbito nacional e internacional a cerca da temática discutida no desenvolvimento da produção desta pesquisa.

A produção de insumos destinados ao consumo humano acarreta excesso de dejetos, seja ele oriundo de vegetais ou animais que servem para produção de biogás no qual atua diretamente na utilização desses dejetos, destinando novos fins. Dessa forma contribuem com o desenvolvimento econômico, ambiental e tecnológico como forma de alternativas para realização de atividades sustentáveis rurais e urbanas.

\section{REFERÊNCIAS}

ABREU, F. V. Biogás: Economia, Regulação e Sustentabilidade. Rio de Janeiro: Interciência, 2014, p. 196.

ABREU, F. V. Biogás de Lixo em aterros sanitários. Uma análise de viabilidade técnica e econômica do seu aproveitamento energético. Blucher, 2011. 1ªedição, p. 166.

ARAUUJO, Ana Paula Caixeta. Produção de biogás a partir de resíduos orgânicos utilizando biodigestor anaeróbico. Uberlândia. Monografia (Engenharia Química), Faculdade de Engenharia Química. Universidade Federal de Uberlândia. Uberlândia, p. 42. 2017. Disponível em: http://repositorio.ufu.br/bitstream/123456789/20292/3/Produ\%c3\%a7\%c3\%a3oBiog\%c3\%a1sRes \%c3\%adduos.pdf Acesso em: 30 mai. 2021.

BARBOSA, G.;LANGER,M. Uso de biodigestores em propriedades rurais: uma alternativa à sustentabilidade ambiental. Unoesc \& Ciência - ACSA, Joaçaba, v. 2, n. 1, p. 87-96, 2011.

BOND, T.; TEMPLETON, M. R. History and future of domestic biogas plants the developing world. Energy for Sustainable Development, v. 15, n. 4, p.347-354, 2011.

BÓCOLI, M. E.; MANTOVANI, J. R.; MIRANDA, J. M.; MARQUES, D. J.; SILVA, A. B. Soil chemical properties and maize yield under application of pig slurry biofertilizer. Revista Brasileira de Engenharia Agrícola e Ambiental, Campina Grande, v. 21, n. 10, p. 42, 2016.

BORTOLON, B; MENDES. M, S, S. A Importância da Educação Ambiental para o Alcance da Sustentabilidade. Revista Eletrônica de Iniciação Científica. Itajaí, Centro de Ciências Sociais e Jurídicas da UNIVALI, v. 5, n. 1, p.118-136, 2014. 
BROWNE, J. D.; MURPHY, J. D. Assessment of the resource associated with biomethane from food waste. Appl. Energy, v. 104, p. 170-177, 2013.

BÜHRING,G.M.B.,SILVEIRA.V,C,P. O biogás e aprodução de suínos do Sul do Brasil. Rev Brasileirade energias renováveis,v.5, n.2, p. 726- 734, 2016.

CAVALCANTE, C. Sustentabilidade: mantra ou escolha moral? Uma abordagem ecológicaeconômica. Estudos avançados, v. 26, n. 74, p. 35- 50, 2012.

COHEN, B; KIETZMANN, J. R. Mobility Business Models for the Sharing Economy. Organization. Environment, v. 27, n. 3, p. 279- 296, 2014.

DHANALAKSHMI, S. V.; RAMANUJAM, R. A. Biogas generation in a vegetable waste anaerobic digester: An analytical approach. Research Journalof Recent Sciences, v. 1, n. 3, p. 41- 47, 2012.

DOS SANTOS, E. B.; DE NARDI JUNIOR, G. Produção de biogás a partir de dejetos de origem animal. Tekhne e Logo, v. 4, n. 2, p.80-90, 2013.

ÉL PAÍS, 2018. União Europeia estabelece cota de 32\% de energias renováveis para 2030. Disponível em: https://www.europarl.europa.eu/ftu/pdf/pt/FTU_2.4.9.pdf Acessado em 25 de nov. de 2020, p. 1- 7.

FERNANDES FILHO, A. C.; SANTANA, C. O. S.; GATTAMORTA, M. A. Utilização de biodigestores para geração de energia elétrica a partir de dejetos de suínos no Brasil. INOVAEJournal of Engineering, Architecture and Technology Innovation, v. 6, p. 67- 84, 2018.

GOLDEMBERG, José; PALETTA, Francisco Carlos. Energias Renováveis: Série Energia e Sustentabilidade. São Paulo: Blucher, 2012, p.110.

HARRIS J. M.; ROACH B. Environmental and Natural Resource Economics: A Contemporary Approach, Tufts University, Medford, MA, USA, 2013, p. 600.

HEYDT, A. R; CREMONEZ, P.A; MEIER, T. R.W; TELEKEN, J. G. Avaliação da Produção de Biogás por Digestão Anaeróbia de Biopolímero de Amido de Batata. Revista Gestão \& Sustentabilidade Ambiental, [S.1.], v. 9, n. esp, p. 311-328, 2020.

KHALID, A. et al. The anaerobic digestion of solid organic waste.Waste Management, v.3, n.8, p. $1737-44,2011$.

KOMINKO, H, et al. The possibility of organo-mineral fertilizer production from sewage sludge. Waste and Biomass Valorization, v. 36, n. 5, p. 1781- 1791, 2017.

LORA, E. E. S; VENTURINI, O. J. Biocombustíveis. Rio de Janeiro: Interciência, 2012, p. 1. 200.

LI, Y. et al. Solid-state anaerobic digestion for methane production from organic waste. Renew.Sust. Energ. Rev, v. 91, n.4, p. 821- 826, 2011. 
MAYER, Mateus Cunha. Estudo da influência de diferentes inóculos no tratamento anaeróbio de resíduos sólidos orgânicos. 2013. 70p. Dissertação (Mestrado em Tecnologia Ambiental) 2013.

MILANEZ et al. Biogás de resíduos agroindustriais: Panorama e Perspectivas. BNDES Setorial, n. 47, p. 221-276, 2018.

MULLER, A. M; SILVEIRA, O. D. DA; NARA, E. O. B; KIPPER, L. M; MORAES, J. A. R. Um olhar exploratório sobre os resíduos de serviços de saúde para os cursos da área da saúde nu a universidade comunitária do sul do Brasil. Revista Eletrônica em Gestão, Educação e Tecnologia Ambiental, v. 21, n. 1, p. 327- 335, 2013.

MUNCK, L; BORIM-DE-SOUSA, R. Sustainability and competencies in organizational contexts: a proposal of de modelo f interaction. Int. J. Environmentand sustainable development, v. 16, n. 1,p. 394- 411, 2012.

NASCIMENTO, E. P. Trajetória da sustentabilidade: do ambiental ao social, do social ao econômico. Estudos Avançados, São Paulo, v. 26, n. 74, p- 51-64, 2012.

OLIVEIRA, M. M. Como fazer pesquisa qualitativa. 6. ed. Petrópolis: Vozes, 2014, p. 181.

OLIVEIRA, S. V. W. B.; FERREIRA, A. H.; OLIVEIRA, M. M. B. Aproveitamento de resíduos para geração de energia: ecoeficiência e sustentabilidade. ENGEMA: Encontro Internacional sobre Gestão Empresarial e Meio Ambiente, v. 14, p. 197- 200, 2016.

OLIVEIRA, L. D. Os "limites do crescimento" 40 anos depois: das profecias do apocalipse ambiental ao futuro comum ecologicamente sustentável. Revista continentes, Rio de Janeiro, v. 1, n. 1, p. 72- 96, 2012.

PROGRAMA DAS NAÇÕES UNIDAS PARA O DESENVOLVIMENTO-PNUD.

Transformando Nosso Mundo: a Agenda 2030 para o Desenvolvimento Sustentável, p.1-7, 2015. Disponível em: file://C:/Users/creus/Downloads/MATE_TI_199546.pdf.

QUIAO, W.; YAN, X.; YE, J.; SUN, Y.; WANG, W.; ZHANG, Z. Evolution of biogás production from different biomass wasteswith/withouthydrothermalpretreatment. Renewable Energy, v. 36, n. 12, p. 3313- 3318, 2011.

RODRIGUES, D.L; AQUINO, C. F; ESTEVAM, G. P. "Produção de biogás a partir dos esgotos utilizando reatores anaeróbicos do tipo rafa seguido por lodos ativados numa estação de tratamento de esgoto". Omnia Exatas, v. 4, n. 2, p. 103- 109, 2011.

RYCHEBOSH, E., DROUILAN, M, H. E. Techniques for transformation of biogás to biomethane. Biomass e Bioenergy, v. 35, n. 5, p. 1633- 1645, 2011.

SALAS-ZAPATA, W; RIOS-OSORIO, L.; CASTILHO, JAD. La ciência emergente de La sustentabilidad: de La práctica cientificahacia La constitucíon de umaciência. Interciencia, v. 2, n. 9, p- 641- 654, 2011. 
SEVERO, E. M; SOUSA, H. J. Avaliando a sustentabilidade das edificações através de ferramentas qualitativas e quantitativa. RISTI- Revista Ibérica de Sistemas e Tecnologias de Informação, n. 23, p- 13-21, 2016.

SILVA, A. dos S. Análise de componentes tóxicos em resíduos sólidosurbanos. 2016. 161p. Tese (Doutorado em Ciência e Engenharia de Materiais) Universidade Federal de Campina Grande. Campina Grande-PB, 2016.

SILVA, W. T. L.; NOVAES, A. P. L.; KUROKI, V.; ALMEIDA, L. F.; MAGNONI JÚNIOR, M. L. Avaliação físico-química de efluente gerado em biodigestor anaeróbio para fins de avaliação de eficiência e aplicação como fertilizante agrícola. Química Nova,v. 12, n. 1, p. 35- 40, 2012.

SILVA, P. C. da; AMARAL A. A. do. Tratamento de Dejetos Suínos com Biorreator UASB. Revista Verde de Agroecologia e Desenvolvimento Sustentável, Mossoró, v. 8, n. 2, p. 141-147, 2013.

SILVA, J. E. P. da. Avaliação técnica e econômica de um biodigestor de fluxo tubular: estudo de caso do modelo implantado na ETEC “Orlando Quagliato" em Santa Cruz do Rio Pardo, Sp, 2016, 69p. Dissertação (Mestrado em Agronomia). Universidade Estadual Paulista "Júlio de Mesquita Filho. Botucatu- SP. 2016.

SITORUS, B.; PANJAITAN, S.D. Biogas recovery from anaero bicdigestion process of mixed fruit-vegetable wastes. Energy Procedia, v. 35, n. 4, p. 176- 182, 2013.

SONIA, V. W. B. O.; ALESSANDRA, H. F.; MARCIO, M. B. O. Aproveitamento de resíduos para geração de energia: ecoeficiência e sustentabilidade. ENGEMA. 2016, p. 2359- 1048.

SUNADA, N. S.; ORRICO, A. C. A.; ORRICO JR. M. A. P.; VARGAS JR. F. M.;GARCIA, R. G.; FERNANDES, A. R. M. Potential of biogas and methane production from anaerobic digestion of poultry slaughterhouse effluent. Revista Brasileira de Zootecnia, Viçosa, v. 41, n. 11, p. 23792383, 2012.

STRASSBURG, U; OLIVEIRA, N. M.; ROCHA JUNIOR, W. F. O potencial de geração de Biogás proveniente da criação de suínos no Oeste do Paraná: um estudo exploratório. Revista em Agronegócio e Meio Ambiente, v. 8, n. 12, p. 803- 818, 2016.

TIETZ, C. M.; SOARES, P. R. H.; SANTOS, K. G. Produção de energia pela biodigestão anaeróbia de efluentes: o caso da bovinocultura. Revista Acta Iguazu, Cascavel, v. 2, n. 3, p. 15 29, 2013.

VELÁZQUEZ, S. M.S G., SANTOS, S., MOREIRA, J. R., COELHO, S. T. Geração de Energia Elétrica em Comunidades Isoladas na Amazônia a partir de Biomassa Sustentável: Projeto ENERMAD, 2014, p.14.

ZUCCA, R; VIEIRA NETO, J. G; SANTOS, R. C.; LOVATTO. J; COSTA, M. V. Uso de resíduos de construção como agregado graúdo destinado à confecção de blocos para alvenaria de vedação. Enciclopédia Biosfera, 2018, p. 1351. 